\title{
Cost and Access to Drug Treatment within the United States Prison System
}

\author{
Grant Voyles CCS* \\ Armstrong State University, USA
}

Submission: August 04, 2017; Published: August 21, 2017

*Corresponding author: Grant Voyles CCS, CAC II, NCAC, MPH Graduate Student, Armstrong State University, Savannah, USA, Tel: 770-312-2745; Email: grantvoyles@gmail.com

\begin{abstract}
This paper explores multiple studies and articles regarding the cost and access to substance use disorder treatment in United States prisons and correctional institutions. The articles make clear that there is a large need for treatment in the correctional system and that proper drug treatment can be a very cost effective in reducing recidivism. The research shows that there are multiple barriers to access but do not have a clear consensus on how to remove those barriers and promote easier access to treatment
\end{abstract}

Keywords: Substance use disorder; Prison; Drug; Treatment; Recidivism

\section{Introduction}

The prison population in the United States is the largest in the world. Roughly 2.2 million prisoners are incarcerated in the America and the U.S. operates 4,575 prisons, also the most in the world [1] This is a trend that has been growing for the past several decades- in 1972 the U.S. prison population was fewer than 200,000 [2,3] states that, "mass incarceration of Americans began in earnest in the 1980s, attributed largely to the War on Drugs." While a "tough on crime" stance has sold well with politicians and the general public it has had unforeseen consequences on the American society, from the inmate to the taxpayer.

\section{Background}

One of the more prominent issues is that 95 percent of the prisoner population in the United States will eventually be released [4]. This begs the question- what type of inmate does society wants re-entering into it? How can the system help a criminal change so that he does not re-offend and become incarcerated again? There is no magic solution to these questions but there is a starting point- providing substance use disorder treatment to offenders who need it. Prisons hold a disproportionate amount of American society's drug abusers Zarkin et al. [5] states that, "approximately 50\% of state prisoners meet the criteria for a diagnosis of drug abuse or dependence; however, only $10 \%$ of prisoners receive drug treatment. This is a staggering gap, especially when one takes into account all that a drug problem can, and often does, entail even besides the use of substances themselves- criminal activities to afford the drugs, high risk behaviors such as driving under the influence and sharing needles, loss of wages due to illness related to drug use, the effects on the family of someone incarcerated for a drug related crime. Prisons were not built to be pleasant environments but that does not necessarily mean that learning cannot take place in one. Rehabilitation in prison is still a relatively new concept but one worth examining if the United States is serious about reducing its recidivism rate. Two obstacles that must be cleared are the cost and access to substance use disorder treatment. Is treatment cost effect? And who has access to drug treatment while incarcerated? Should they? Treatment for offenders who meet DSM V criteria for substance use disorder within the prison systems has come and gone in waves in America.

The fist large scale treatment effort was opened in Lexington Kentucky in 1935 under the name "United States Narcotics Farm" [6]. Despite some success with treatment (the prison is still open today but under a different name) treatment within the U.S. system had a hard time taking hold. Many a politician, from local to federal officials, makes claims of being "tough on crime" as an election promise. But the underlying belief that rehabilitation of inmates does not work comes from a different source. In 1974 Robert Martinson published, "What Works? Questions and Answers about Prison Reform."

In this study Martinson concluded that there is, "little reason to hope that we have in fact found a sure way of reducing 


\section{Global Journal of Addiction \& Rehabilitation Medicine}

recidivism through rehabilitation." With regards to counseling and group therapy Martinson concludes, "The burden of evidence is not encouraging" and for those in medication assisted therapy (MAT) for drug use, "there was only a slightly improvement in their subsequent behavior; this improvement disappeared within a year." While Martinson's study was later criticized for its unscientific methods his work created what is known as the "nothing works" doctrine of prison rehabilitation [7]. His work was embraced by politicians, and inspired a wave of strong sentencing and cancellation of rehabilitation programs [8].

\section{Literature Review}

When looking at access of drug rehabilitation for inmates one has to first look at if inmates have a legal right to such services. One could argue that prison is meant to be a punishment and that rewarding inmates with "free" drug treatment goes against the point of incarceration. The Diagnostic and Statistical Manual of Mental Disorders, Fifth Edition (DSM-5) defines substance use disorder (formerly substance abuse or substance dependency) as a disease (American Psychiatric Association, 2013). While there has not been a Supreme Court case involving an inmate's access to substance use disorder, there have been several cases regarding prisoners and medical care. Estelle v. Gamble [9] established that under the Eighth Amendment prison officials are obligated to provide prisoners with adequate medical care; in order to prevail on a constitutional claim of inadequate medical care, inmates must show that prison officials treated them with "deliberate indifference to serious medical needs."

Farmer v. Brennan [10] set forth that a prison official demonstrates "deliberate indifference" if he or she recklessly disregards a substantial risk of harm to the prisoner. Bradley v. Puckett [11] set forth that the prison official does not need to know of a specific risk from a specific course. While there is no specific ruling regarding substance use disorder treatment, it can be argued that since this is treatment for a disease that and that over 47,000 Americans died from drug overdoses in 2014 [12] that substance use disorder is a serious medical need. While the court has not ruled that, there is no Supreme Court ruling blocking a prisoner's participation in a drug treatment program while incarcerated.

As stated earlier 50 percent of prisoners meet the criteria for a diagnosis of substance use disorder and thus a need for treatment but only 10 percent actually receive drug treatment Zarkin et al. [5]. This leaves about one million inmates with the need for treatment not receiving it. The barriers to access are more than that, as studies reveal racial/ethnic disparities in utilization and referrals to drug treatment programs in American correctional institutions. Some of this is due to the racially disproportionate sentencing. Nicosia, MacDonald, and Arkes [13] states that, "despite substantial evidence that minorities are overrepresented in the drug arrestee population, they remain a relatively small share of criminal justice referrals to treatment."
Hispanics and Blacks contributed to about 60 percent of prison admission [2] but only 35 percent of admissions into alcohol and other drug treatment programs.

To an extent this lack of access mirrors that of the outside world. An evaluation of managed behavioral care by state Medicaid agencies found that the percent of Medicaid-eligible Black or Hispanic clients who accessed treatment remained lower than that of whites every year of the study [14].The same article states that Blacks are most likely to be incarcerated for a drug offense but that Whites are most likely to have mental health counseling and substance abuse treatment as part of their sentencing. While there is no clear answer as to why this racial divide for treatment exists, it is there and limits the access to substance use disorder treatment for a group of the inmate population.

Screening is another issue that plays into a prisoner's access to substance use disorder treatment while incarcerated. If so many inmates meet the diagnostic criteria, then why are they not being placed in treatment programs? One issue that makes screening in a correctional setting so difficult is the larger number of persons arrested in America. In 2012 alone the FBI estimates that over 12 million people were arrested in the U.S. Not all of those individuals will be serving time in jail or prison but millions of them will. The American Correctional Association's (ACA) Standards for Adult Local Detention Facilities state that a high-fidelity jail admissions process should include: "a criminal-history check, a photograph of the inmate, fingerprints, an inventory of personal property, collection of personal information for mailing and visitation lists, assignment of the inmate's registered number, an assessment of general appearance and behavior, verification of identity, and screenings for any risks and needs associated with medical, dental, mental health, drug or alcohol use, or suicidal tendencies" [15]. However one study found that 34 percent of inmates were not flagged for having a mental health diagnosis (which includes substance use disorder) despite having a documented history of treatment. While screening is no use of a full diagnostic tool, it is useful in helping inmates be placed within the proper programs for their need. More research is need for ways to improve the efficiency and effectiveness of inmate screens as well as communication between correctional institutions. Correctional institutes in America are expensive.

The average cost per inmate is 31,286 dollars each year, this totals about 39 billion dollars annually that the taxpayers pay [16]. Many of the inmates in America's prison system have been inmates before and are repeat offenders. Recidivism is a major problem in the U.S. criminal justice systems with about 76 percent of released offenders will be re-arrested within five years [17]. Reducing recidivism by even a small amount would greatly reduce the overall cost of incarceration in the U.S. While the price of drug treatment in the outside world varies greatly depending on factors such as type of treatment provided and 
length of treatment the National Institute on Drug Abuse (NIDA) reports that one full year of methadone maintenance treatment is approximately $\$ 4,700$ per patient (2012).

INIDA illustrates the cost effectiveness further stating,"every dollar invested in addiction treatment programs yields a return of between $\$ 4$ and $\$ 7$ in reduced drug-related crime, criminal justice costs, and theft. When savings related to healthcare are included, total savings can exceed costs by a ratio of 12 to 1 . Major savings to the individual and to society also stem from fewer interpersonal conflicts; greater workplace productivity; and fewer drug-related accidents, including overdoses and deaths" (2012). Numerous projects have investigated the effectiveness of substance abuse treatment programs provided within correctional institutions, "most of these studies support the premise that criminal sanctioning without provision of rehabilitative services may not succeed in reducing recidivism" [18].

To be cost-effective, prison-based drug treatment programs must be effective in reducing recidivism. A variety of treatment methods are used within the correctional system, most tend to share the qualities of a group based approach, in which peers support each other to develop positive behaviors and to work towards recovery [19]. Treatment does not have to be limited to that model however as an, "increasing range of evidencebased treatment modalities have been found to be effective in improving outcomes from substance use disorder" [20].

Studies on the reducing of recidivism among those prisoners who received drug treatment while incarcerated reveal that 75 percent of studies found a reduction in re-incarceration rates and that 70 percent of studies examining relapse found a reduction in relapse among those inmates who had received treatment versus those inmates who had not [19]. Those studies that included aftercare (post-incarceration) programs yielded more positive results than those that did not, "the effect of aftercare is encouraging to public health oriented interventions with exoffenders with substance abuse histories; this is particularly the case since after care programs make a positive difference to reducing drug misuse-related re-offending" [19]. Diversion programs such as mental health courts and drug courts aim to bring down the high number of individuals with mental illness and/or substance use disorders who are rearrested for minor offenses, like property theft, possession of illegal substances, public intoxication, or parole and probation violations. Hautala [15] the economic and social cost of substance use disorder and incarceration is so great that any reduction can have a major impact.

Average weekly costs of in-prison programs ranges from 30 to 68 dollars McCollister et al. [21] This illustrates the modest increase in cost that it would take to implement these programs and that the reduction in re-offenders would in a sense pay for the programs. The societal savings of implementing drug treatment would also be impressive. If only 10 percent of drug-addicted offenders received drug rehabilitation instead of jail time, the criminal justice system would save $\$ 4.8$ billion compared to current costs. If 40 percent of addicted offenders received treatment instead of jail, those savings would rise to $\$ 12.9$ billion Zarkin et al [5].

It is also worth examining how far reaching the effects of a person drug addiction can be which often include: medical care and health costs for overdose, accidental injury under the influence, and chronic illness caused by drug use, bail, court costs, lawyer fees, and other legal fees caused by drug-related arrest, loss productivity of the incarcerated person and an inability to work and bring in money, and the cost of supporting any children born to the incarcerated person if the children are removed by the state. "Mortality from drug overdose has been reported to be particularly high after release from prison" [22]. While substance use disorder is treatable, many inmates- especially those who do not receive treatment while incarcerated- will return to drug use when released and death from overdose is more common in those recently released from prison than that of the general population.

"In people released from prison $34 \%$ of all-cause deaths in men and $50 \%$ in women were potentially attributable to substance use disorders"[22]. While substance uses disorder increases the risk of death in recently released inmates, these inmates will not die from a drug overdose if that do not use drugs. Providing substance use disorder treatment while incarcerated will lower than risk of relapse thusly lowering their risk of mortality due to overdose. Further long-term studies may be needed to evaluate the ability for prison-based treatment to reduce the mortality rate among recently released inmates.

\section{Conclusion and Further Study}

The cost and access of drug treatment programs for incarcerated individuals is a complex issue with many factors to consider. The majority of studies reviewed agree that incarceration is expensive and that effective drug treatment can reduce recidivism and therefore reduce overall costs to the state and taxpayer. However, few studies were in agreement on what type of treatment is the most effective for prisoners with substance use disorder. Given the varying cost of different treatment methods (e.g. methadone maintenance versus a therapeutic community) more research into the different modalities is need to determine what will be most cost effective and will reduce recidivism the most. Despite a need for substance use disorder treatment and the cost reducing results significant barriers to access still exist. One such barrier is that there is no legal right for inmates to access treatment at this time.

While there is no court ruling denying access to treatment, drug treatment while incarcerated as a right may be an issue that the court must rule on in the future. Another barrier is the 
disproportional rate in which White offenders are more likely to be referred to treatment than Black or Hispanic offenders. The literature reviewed offers no clear evidence as to why this is happening but further study is need on this possibly systemic issue. The final barrier noted in the literature reviewed is proper screening for substance use disorder upon an inmate's admission to a correctional facility. Improper screening may be the result of under-trained staff, ineffective screening tools, or under-utilized screening. Further research is needed into how correctional institution conduct screenings and assessments for substance use disorder before proper solutions can be proposed.

\section{References}

1. Kaeble D, Glaze L, Tsouti A, Minton T (2104) Correction Populations in the United States, Bureau of Justice Statistics.

2. Carson E, Sabol W (2012) Prisoners in 2011 U.S Department of Justice, Bureau of Justice Statistics. Office of Justice Programs.

3. Nowotny K (2014) Race/ethnic disparities in the utilization of treatment for drug dependent inmates in U.S. State correctional facilities. Addictive Behaviors 40: 148-153.

4. Binswanger I, Nowels C, Corsi K, Long J, Booth R, et al. (2011) From the prison door right to the sidewalk, everything went downhill, A qualitative study of health experiences of recently released inmates. International Journal of Law and Psychiatry 34(4): 249-255.

5. Zarkin G, Cowell A, Hicks K, Mills M, Belenko S, et al. (2015) Lifetime Benefits and Costs of Diverting Substance-Abusing Offenders From State Prisons. Crime \& Delinquency 61: 829-850.

6. Kosten T, Gorelick A (2002) The Lexington Narcotics Farm. American Journal of Psychiatry 159: 22.

7. Sarre R (2001) Beyond 'What Works?'A 25-year Jubilee Retrospective of Robert Martinsons Famous Article. Australian \& New Zealand Journal of Criminology 34: 38-46.

8. Barkow R (2009) The Court of Life and Death: The two tracks of constitutional sentencing law and the case for uniformity. Michigan Law Review 107: 1173.

9. Estell v Gamble (1976)
10. Farmer v Brennan (1994)

11. Bradley v Puckett (1998)

12. Rudd R, Aleshire N, Zibbell J, Gladden R (2016) Increases in Drug and Opioid Overdose Deaths. Morbidity and Mortality Weekly Report 64(50): 1378-1382.

13. Nicosia N, MacDonald J, Arkes J (2013) Disparities in Criminal Court Referrals to Drug Treatment and Prison for Minority Men. American Journal of Public Health 103(6): e77-84.

14. Nowotny K (2014) Race/ethnic disparities in the utilization of treatment for drug dependent inmates in U.S. State correctional facilities. Addictive Behaviors 40: 148-153.

15. Hautala M (2015) In the Shadow of Sandra Bland: The Importance of Mental Health Screening in U.S. Jails. Texas Journal of Civil Liberties \& Civil Rights 29: 89-126.

16. Henrichson C, Delaney R (2012) The Price of Prisons What Incarceration Costs Taxpayers. Vera Institute of Justice pp. 1-22.

17. Durose M, Cooper A, Snyder H (2014) Recidivism of Prisoners Released in 30 States in 2005: Patterns from 2005 to 2010. Bureau of Justice Statistics Special Report.

18. French M, Fang H, Fretz R (2010) Economic evaluation of a prerelease substance abuse treatment program for repeat criminal offenders. Journal of Substance Abuse Treatment 38(1): 31-41.

19. Galassi A, Mpofu E, Athanasou J (2015) Therapeutic Community Treatment of an Inmate Population with Substance Use Disorder: Post-Release Trends in Re-Arrest, Re-Incarceration, and Drug Misuse Relapse. International Journal of Environmental Research and Public Health. 12(6): 7059-7072.

20. Werb D, Kamarulzaman A, Meacham M, Rafful C, Fischer B, et al. (2015) The effectiveness of compulsory drug treatment: A systematic review. International Journal of Drug Policy 28: 1-9.

21.Mc Collister K, French M, Prendergast M, Wexler H, Sacks $S$, et al. (2003) Is In-Prison Treatment Enough? A Cost-Effectiveness Analysis of Prison-Based Treatment and Aftercare Services for SubstanceAbusing Offenders. Law \& Policy 25: 63-82.

22. Chang Z, Lichtenstein P, Larsson H, Fazel S (2015) Substance use disorders, psychiatric disorders, and mortality after release from prison: a nationwide longitudinal cohort study. Lancet Psychiatry 2: 422-430.

\section{Your next submission with Juniper Publishers will reach you the below assets}

- Quality Editorial service

- Swift Peer Review

- Reprints availability

- E-prints Service

- Manuscript Podcast for convenient understanding

- Global attainment for your research

- Manuscript accessibility in different formats

( Pdf, E-pub, Full Text, Audio)

- Unceasing customer service

Track the below URL for one-step submission https://juniperpublishers.com/online-submission.php 